University of New Hampshire

University of New Hampshire Scholars' Repository

$9-2004$

\title{
Measurement of In Situ Acoustic Properties for the ONR Geoclutter Program
}

\author{
Larry A. Mayer \\ University of New Hampshire, larry.mayer@unh.edu \\ Barbara J. Kraft \\ University of New Hampshire, Durham \\ Luciano E. Fonseca \\ University of New Hampshire, Durham, luciano@ccom.unh.edu
}

Follow this and additional works at: https://scholars.unh.edu/ccom

Part of the Oceanography and Atmospheric Sciences and Meteorology Commons

\section{Recommended Citation}

Mayer, Larry A.; Kraft, Barbara J.; and Fonseca, Luciano E., "Measurement of In Situ Acoustic Properties for the ONR Geoclutter Program" (2004). Center for Coastal and Ocean Mapping. 1197.

https://scholars.unh.edu/ccom/1197

This Report is brought to you for free and open access by the Center for Coastal and Ocean Mapping at University of New Hampshire Scholars' Repository. It has been accepted for inclusion in Center for Coastal and Ocean Mapping by an authorized administrator of University of New Hampshire Scholars' Repository. For more information, please contact Scholarly.Communication@unh.edu. 


\title{
Measurement of In Situ Acoustic Properties for the ONR Geoclutter Program
}

\author{
Larry Mayer \\ Center for Coastal and Ocean Mapping \\ University of New Hampshire \\ Durham, NH 03824 \\ phone: (603) 862-2615 fax: (603) 862-0839 email: 1mayer@ccom.unh.edu \\ Barbara Kraft \\ phone: (603) 862-5070 fax: (603) 862-0839 email: bjkraft@ccom.unh.edu \\ Luciano Fonseca \\ phone: (603) 862-1862 fax: (603) 862-0839 email: luciano@ccom.unh.edu \\ Award Number: N00014-00-1-0821 \\ http://www.ccom.unh.edu/
}

\section{LONG-TERM GOALS}

The long-term objective of the GEOCLUTTER program is to understand the causes and implications of geologic clutter (reverberation) in a geologically well-characterized shallow-water environment. The field area selected for the GEOCLUTTER program is the mid-outer continental shelf off New Jersey, USA. The New Jersey margin was chosen for the GEOCLUTTER study because the bathymetry and portions of the shallow subsurface of this area had already been mapped in detail as part of an earlier ONR program aimed at understanding the origin of subsurface stratigraphy on continental margins (STRATAFORM). In addition to multibeam bathymetry, 'calibrated' backscatter data (at $95 \mathrm{kHz}$ from the multibeam sonar) was also collected as part of the STRATAFORM program.

\section{OBJECTIVES}

The overall scientific objectives of the GEOCLUTTER program are: 1) to understand, characterize, and predict lateral and vertical, naturally-occurring heterogeneities that may produce discrete acoustic returns at low grazing angles (i.e., "geologic clutter") and then; 2) to conduct precise acoustic reverberation experiments at this site to understand, characterize, and potentially mitigate the geologic clutter.

\section{APPROACH}

In order to meet these objectives and to properly implement acoustic models for the GEOCLUTTER area, we need to know, or predict, the key acoustic and physical properties throughout the volume of interest (i.e., grain size, density, sound speed, attenuation). The properties of the near-surface seafloor sediments are particularly important. A possible approach to this problem is to use the $95 \mathrm{kHz}$ multibeam backscatter data collected in the region, which may provide information on seafloor sediment properties. If remotely-sensed backscatter data can be used to infer seafloor sediment properties, we would have the ability to make quantitative statements about seafloor properties over large areas of the seafloor and thus the ability to address a number of important navy-related problems. The relationship between backscatter and sediment properties remains ambiguous, and as of 


\section{Report Documentation Page}

Form Approved

OMB No. 0704-0188

Public reporting burden for the collection of information is estimated to average 1 hour per response, including the time for reviewing instructions, searching existing data sources, gathering and maintaining the data needed, and completing and reviewing the collection of information. Send comments regarding this burden estimate or any other aspect of this collection of information,

including suggestions for reducing this burden, to Washington Headquarters Services, Directorate for Information Operations and Reports, 1215 Jefferson Davis Highway, Suite 1204, Arlington

VA 22202-4302. Respondents should be aware that notwithstanding any other provision of law, no person shall be subject to a penalty for failing to comply with a collection of information if it

does not display a currently valid OMB control number.

1. REPORT DATE

29 SEP 2004

2. REPORT TYPE

3. DATES COVERED

00-00-2004 to 00-00-2004

4. TITLE AND SUBTITLE

Measurement of In Situ Acoustic Properties for the ONR Geoclutter

Program

6. AUTHOR(S)

5a. CONTRACT NUMBER

5b. GRANT NUMBER

5c. PROGRAM ELEMENT NUMBER

5d. PROJECT NUMBER

5e. TASK NUMBER

5f. WORK UNIT NUMBER

7. PERFORMING ORGANIZATION NAME(S) AND ADDRESS(ES)

8. PERFORMING ORGANIZATION

REPORT NUMBER

Center for Coastal and Ocean Mapping,„University of New

Hampshire,,Durham,,NH,03824

9. SPONSORING/MONITORING AGENCY NAME(S) AND ADDRESS(ES)

10. SPONSOR/MONITOR'S ACRONYM(S)

11. SPONSOR/MONITOR'S REPORT

NUMBER(S)

12. DISTRIBUTION/AVAILABILITY STATEMENT

Approved for public release; distribution unlimited

13. SUPPLEMENTARY NOTES

14. ABSTRACT

15. SUBJECT TERMS

16. SECURITY CLASSIFICATION OF:

a. REPORT

unclassified b. ABSTRACT

unclassified c. THIS PAGE

unclassified
17. LIMITATION OF ABSTRACT

Same as

Report (SAR)
18. NUMBER 19a. NAME OF

OF PAGES RESPONSIBLE PERSON

9 
yet cannot be used as a direct and quantitative predictor of seafloor properties. Attempting to understand the relationship between the multibeam backscatter and the properties of the seafloor is the primary theme of this component of our GEOCLUTTER research program.

In light of the fact that we have not yet successfully been able to produce accurate estimates of seafloor properties from remotely sensed acoustic data, our initial proposal fell back on more traditional means of sampling and laboratory measurements to obtain the needed seafloor property information in the GEOCLUTTER area. Given the coarse-grained, sandy nature of the sediment in the region we were concerned that laboratory measurements of certain properties (in particular sound speed and attenuation) on core samples would not reflect in situ values as sandy sediments tend to de-water very quickly. Thus, the first phase of our GEOCLUTTER work consisted of the development of a simple and relatively inexpensive device designed to measure, in situ, the spatial variability of sound speed and attenuation in near-surface sediments at the GEOCLUTTER site. Our in situ measurements could then be combined with the data collected from cores (by other investigators - John Goff from the University of Texas and Chris Sommerfield from the University of Delaware) as well as other acoustic data (experiments by Charles Holland from Pennsylvania State and Steve Schock from Florida Atlantic University) to better understand the variability of in situ sediment physical and acoustic properties in the GEOCLUTTER area. Subsequent efforts saw the collection of in situ physical and acoustic data at the site of the ONR Martha's Vineyard Mine Burial Experiment (see Mine Burial Annual Report) and future work will involve the collection of in situ data in a very well documented region of Portsmouth Harbor, New Hampshire.

\section{WORK COMPLETED}

Following successful field work in support of the New Jersey GEOCLUTTER program and the Mine Burial program off Martha's Vineyard, we recently completed two small field experiments in nearby Portsmouth Harbor (PH) and Little Bay (LB), NH. Field work included sediment sampling and analysis, and in-situ measurements with ISSAP (In-situ Sound Speed and Attenuation Probe). In our previous field work, ISSAP (see Fig. 1) was configured with four $65 \mathrm{kHz}$ 'omni-directional' acoustic probes and 'time-of-flight' measurements obtained across five acoustic paths. For this field work, new $40 \mathrm{kHz}$ 'directional' probes were used, which increased the frequency range of the measurements, but limited the number of useable acoustic paths to two. Prior to the field work, the additional probes required modifications to ISSAP's transmit/receive board (improvements to the drive electronics and increased gain control) and updates to the data acquisition program in Labview. 


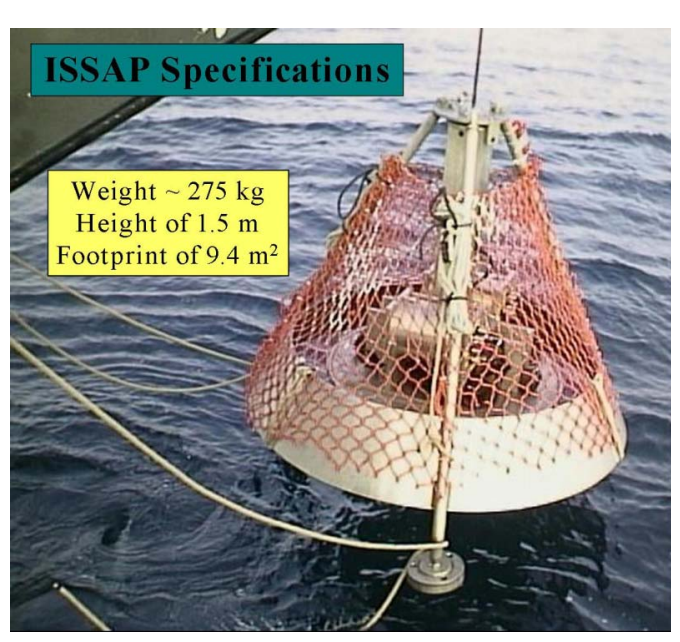

(a)

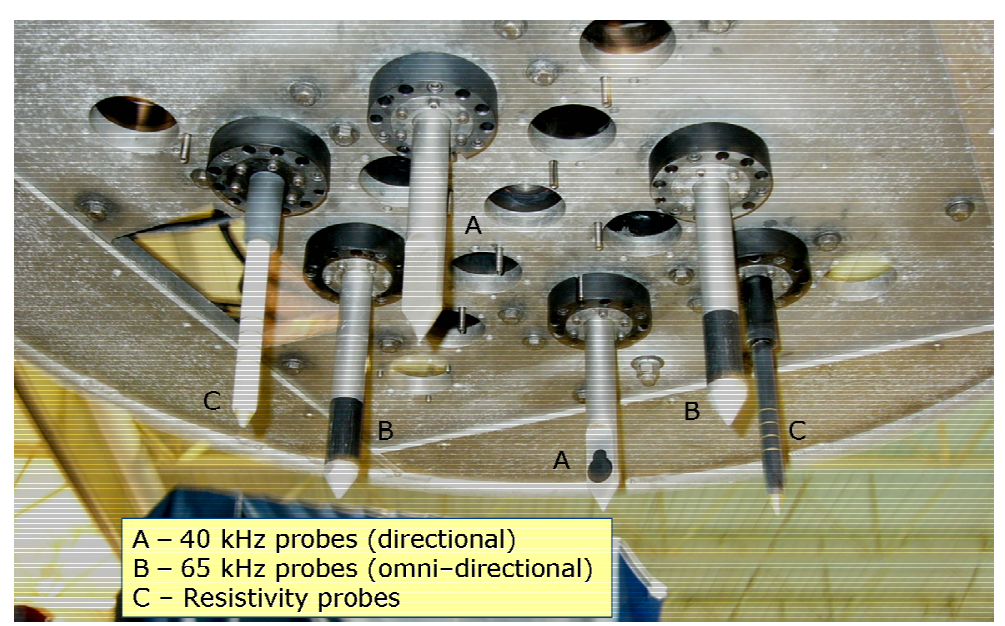

(b)

Figure 1. (a) ISSAP instrument and specifications and (b) underside view of ISSAP
showing the configuration of probes.

In October 2003, sediment sampling was conducted from the R/V Coastal Surveyor and ISSAP measurements made from the R/V Gulf Challenger. Sediment samples were obtained with a Van Veen grab sampler (University of Rhode Island (URI), Marine Geomechanics Lab) in Portsmouth Harbor (20 stations) and Little Bay (28 stations). Sub-samples were taken from the grab samples and analyzed using URI's GeoTek multi-sensor core logger (MSCL). Lab measurements including p-wave sound speed (at $250 \mathrm{kHz}$ ), gamma ray attenuation (saturated bulk density), magnetic susceptibility, and electrical resistivity were completed at $1 \mathrm{~cm}$ intervals on PVC mini-core tubes $(5.08 \mathrm{~cm} \mathrm{ID} \times 8 \mathrm{~cm}$ long). A coarse grain size analysis ( 5 bins) was performed on all grab samples with an additional hydrometer analysis completed for samples with a mud component exceeding $10 \%$. Measurements of permeability and s-wave sound speed on representative samples have not been completed.

Measurements of in-situ sound speed and resistivity (porosity) were completed with ISSAP configured with two orthogonal matched pairs of transducer probes operating at frequencies of 40 and $65 \mathrm{kHz}$ (see Fig. 1b). Measurements were obtained in both Portsmouth Harbor (13 stations) and in Little Bay (23 stations). In April 2004, ISSAP measurements were repeated in Little Bay (24 stations) using the same probe configuration (40 and $65 \mathrm{kHz}$ probes). Additional measurements with ISSAP configured using matched 65 and $100 \mathrm{kHz}$ probes were obtained in Little Bay (18 stations). 


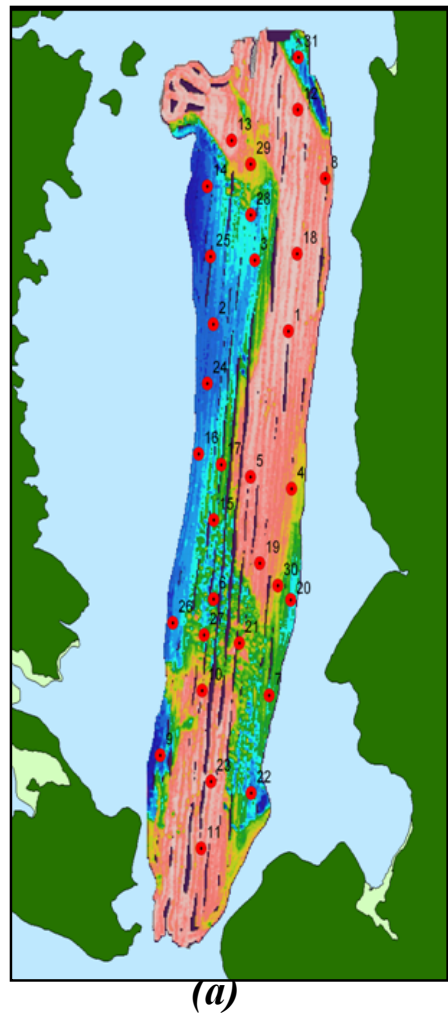

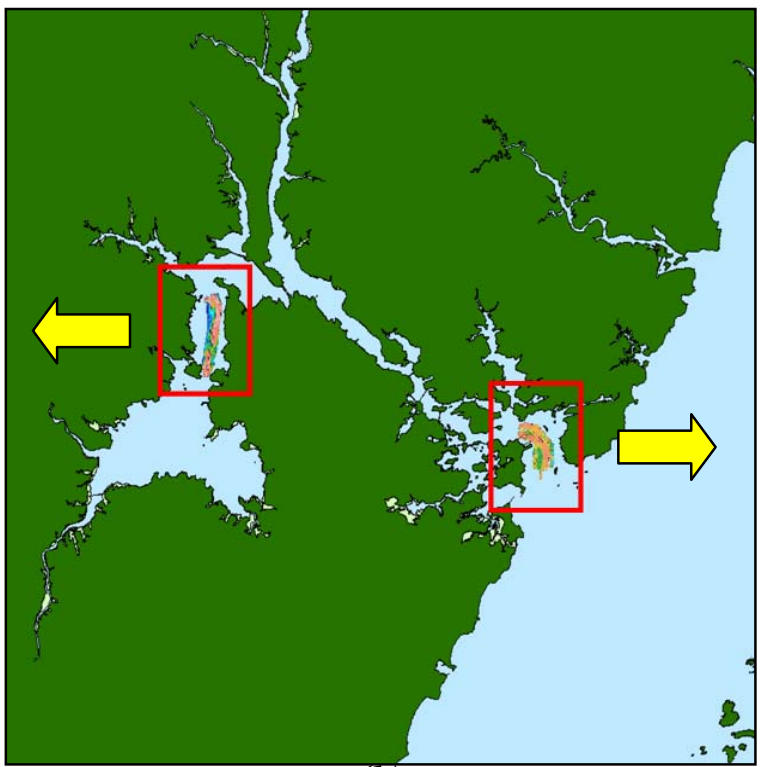

(b)

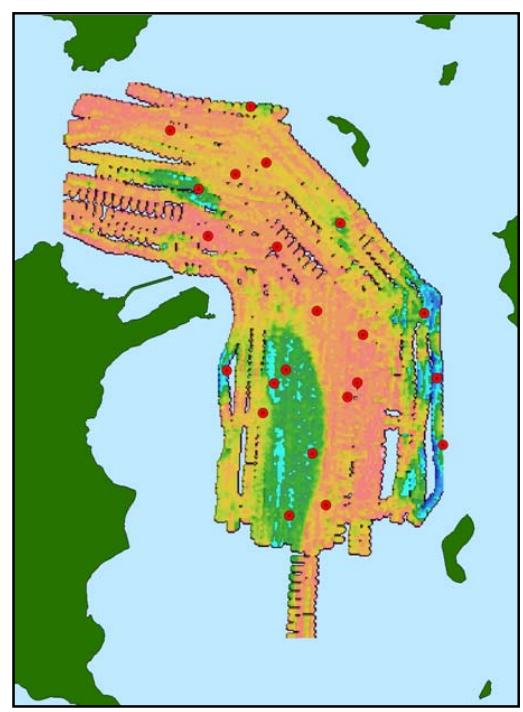

(c)

Figure 2. Piscataqua River Watershed, Portsmouth, NH. ISSAP stations (planned) were selected to represent a range of sediment types and are denoted with a red symbol. (a) Little Bay field area shown (defined) with Simrad EM3000 (300 kHz) multibeam backscatter, (b) Overview showing relative location of the Portsmouth Harbor and Little Bay field areas, and (c) Portsmouth Harbor field area (defined) shown with Simrad EM3000D (300 kHz, dual head) multibeam backscatter.

Most of the ISSAP data has been processed for sound speed at frequencies of 40, 65, and $100 \mathrm{kHz}$. Our initial processing efforts have concentrated on the data collected in Little Bay where the highest quality backscatter data was collected. To explore possible relationships between acoustic backscatter and sediment properties, the EM3000 multibeam backscatter data was processed with a technique called Amplitude Variation with Offset (AVO) [1] a technique commonly used on multi-channel seismic reflection data for the exploration and characterization of subsurface reservoirs. AVO analysis is based on the fundamental assumption that the seismic amplitude varies with the offset between the seismic source and detector and that these variations are inherently related to the acoustic properties of the subsurface reflectors. Multibeam sonars acquire backscatter data over a wide range of incidence angles, making swath data well-suited to an AVO type of analysis.

It is well known that the acoustic backscatter is a function of the acoustic properties of the sediment, mainly the acoustic impedance, the interface roughness, and scattering from heterogeneities within the sediment volume 0 . The direct determination of sediment properties from remotely measured backscatter has been hampered by an inability to separate the component due to the acoustic impedance from the remainder - due to interface roughness and volume heterogeneities. The application of AVO analysis to multibeam backscatter attempts to address this ambiguity.

Processing of the multibeam sonar backscatter data described here is applied to the full-time series data, and not to the beam averaged backscatter value. The AVO analysis is applied to the 'best 
estimate' of the backscatter due to seabed reflection - that is, corrections are performed to remove the time varying gain (TVG) applied during acquisition. Additionally, the beam angle of incidence and ensonified area are corrected (during data acquisition the seafloor is assumed to be flat) based on the local seafloor slope, a correction that may be achieved with co-registered multibeam bathymetry and backscatter.

AVO is applied to a patch of seafloor obtained by averaging a consecutive number of pings, or angular response (backscatter as a function of angle across the swath). Processing is applied independently to the port and starboard angular responses, which are divided into three range intervals based on angle. The 'near range' includes grazing angles from $90^{\circ}$ to $65^{\circ}$, the 'far range' from $65^{\circ}$ to $35^{\circ}$, and the 'outer range' from $35^{\circ}$ to $5^{\circ}$. Within the near range, the mean backscatter, slope, and the $80^{\circ}$ intercept of the averaged backscatter angular response are calculated and stored as AVO attributes (see Fig. 3). For the far range, the calculated AVO attributes include the mean backscatter, slope, and the intercept at $55^{\circ}$. In the outer range, only the mean backscatter is stored as an attribute. One additional AVO parameter, the 'fluid factor', is calculated for each seafloor patch. For that, the background trend line for the survey is defined as the linear regression of all coordinate pairs (slope, intercept) in the slopeintercept plane. The fluid factor attribute is defined as the orthogonal distance of each coordinate pair from the background trend.

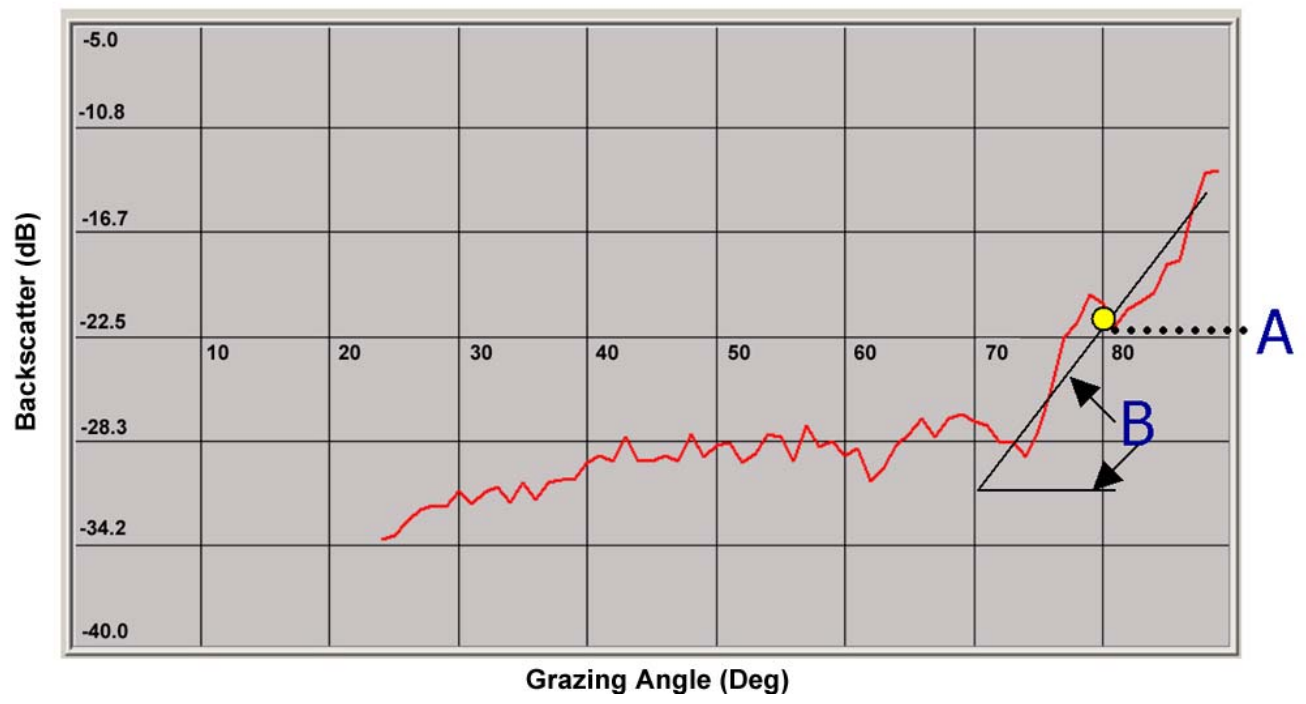

Figure 3. Backscatter as a function of grazing angle; ' $A$ ' represents the near range intercept and ' $B$ ' represents the near range slope.

Once the AVO parameters are calculated, a mathematical backscatter model 0 is used to relate the measured backscatter angular response of each seafloor patch to seafloor properties of acoustic impedance, interface roughness, and fluid factor. According to this modeling, the fluid factor attribute is directly related to the amount of free fluid, normally gas, in the sediment structure. The same AVO parameters that are calculated for the measured backscatter angular response are calculated for the modeled backscatter angular response. A model inversion is performed sequentially by adjusting in order the near range slope; near range intercept; far range intercept, far range slope, and the fluid factor. 


\section{RESULTS}

Sound speed dispersion was observed at a majority of stations excluding the stations with a sound speed approximately that of the overlying seawater. Initial comparisons indicate that the magnitude of the sound speed dispersion is related to the mean grain size. The grain size analysis conducted by URI was initially limited to five grain size bins which did not provide an accurate estimate of the grain size distribution. URI recently completed hydrometer analysis of the mud component (for stations with greater than $10 \%$ mud fraction).

The AVO approach was applied to the Simrad EM3000 multibeam sonar data from Little Bay. The estimated impedance and was compared to the measured ISSAP sound speed. Shown in Figure 4 is the estimated impedance ratio as a function of the ISSAP measured sound speed ratio at a frequency of 40 $\mathrm{kHz}$. Initial results are encouraging and indicate a strong correlation between these two acoustic parameters. Additional field work is required to include a larger sample of sediment types.

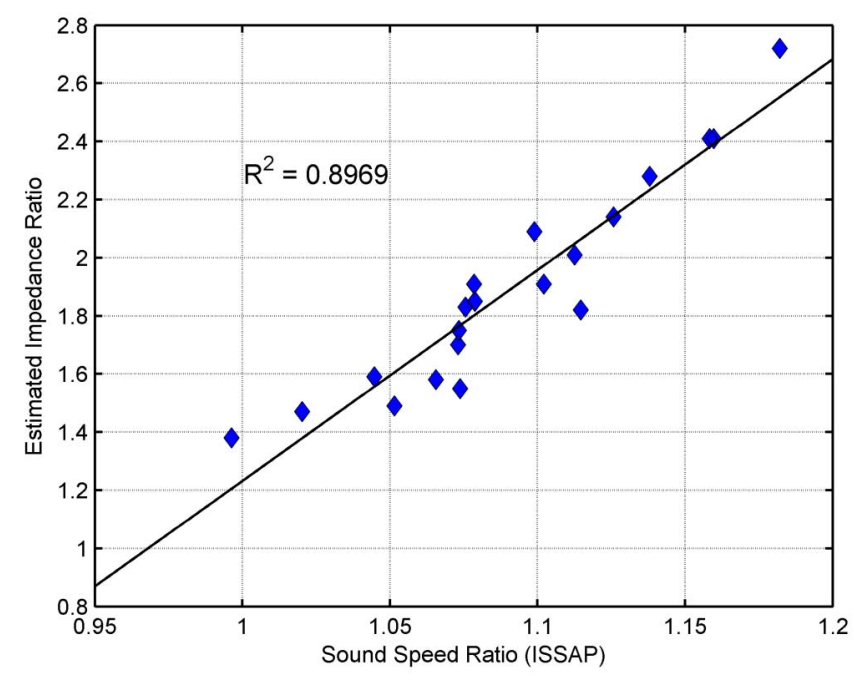

Figure 4. Estimated impedance ratio as a function of ISSAP sound speed ratio at $40 \mathrm{kHz}$.

\section{IMPACT/APPLICATIONS}

The ISSAP has provided a simple and quick way to establish the lateral distribution of sound speed and attenuation variations within the Geoclutter area. These measurements are being compared directly to backscatter values from the multibeam system and to the predictions of impedance and attenuation made from the Chirp Sonar by Schock. They also provide information on the range of natural variability that is very relevant to other Navy programs (e.g., Capturing Uncertainty DRI and Mine Burial Program - where it was used).

The work described above will play a key part in the overall development of robust seafloor characterization approaches, particularly through helping to better constrain the relationship of highfrequency backscatter to seafloor properties. It will also provide critical information on the 
relationship of in situ properties to those made in the laboratory as well as those extracted remotely from the inversion of seismic (chirp sonar) data.

\section{TRANSITIONS}

Data requested by Chris Jenkins for incorporation into global sediment property database

\section{RELATED PROJECTS}

Uncertainty DRI, Mine Burial DRI

\section{REFERENCES}

[1] Castagna, J. P. and Backus, M. M., Eds., "Offset-dependent reflectivity - theory and practice of AVO analysis," Society of Exploration Geophysicists, 1993.

[2] Jackson, D. R. and Briggs, K. B., "High-frequency bottom backscattering: roughness versus sediment volume scattering," J. Acoust. Soc. Am., Vol. 92, No. 2, pp. 962-977, 1992.

[3] Fonseca, L., Mayer, L., Orange, D., and Driscoll, N., "The high-frequency backscattering angular response of gassy sediments: model/data comparison from the Eel River margin, California," $J$. Acoust. Soc. Am., Vol. 111, No. 6, pp. 2621-2631, June 2002.

\section{PUBLICATIONS}

Kraft, B. J., Mayer, L. A., Simpkin, P., Lavoie, P., Jabs, E., Lynskey, E. and Goff, J. A., Calculation of in-situ acoustic wave properties in marine sediments, In Impact of Littoral Environmental Variability on Acoustic Predictions and Sonar Performance, ed. by N. G. Pace and F. B. Jensen, Kluwer Academic Publishers, The Netherlands, pp. 123-130, 2002. [published, refereed]

Mayer, L. A., Kraft, B. J., Simpkin, P., Lavoie, P., Jabs, E., and Lynskey, E., "In-situ determination of the variability of seafloor acoustic properties: an example from the ONR GEOCLUTTER area," In Impact of Littoral Environmental Variability on Acoustic Predictions and Sonar Performance, ed. by N. G. Pace and F. B. Jensen, Kluwer Academic Publishers, The Netherlands, pp. 115 - 122, 2002. [published, refereed]

Goff, J. A., Kraft, B. J., Mayer, L. A., Schock, S., Sommerfield, C. K., Olson, H. C., Gulick, S. P. S., and Nordfjord, S., "Seabed characterization on the New Jersey middle and outer shelf: Correlability and spatial variability of seafloor sediment properties," Marine Geology, Vol. 209, Issues 1-4, pp. 147172, August 2004. [published, refereed].

Kraft, B. J., Overeem, I., Holland, C. W., Pratson, L. F., Syvitski, J. P. M., and Mayer, L. A., "Stratigraphic model predictions of geoacoustic properties," IEEE J. Oceanic Eng., September 2004. [submitted, refereed]

Kraft, B. J., Fonseca, L., Mayer, L. A., McGillicuddy, G., Ressler, J., Henderson, J., and Simpkin, P., "In-situ measurement of sediment acoustic properties and relationship to multibeam backscatter," $J$. Acoust. Soc. Am., Vol. 115, No. 5, Pt. 2, pg. 2401, May 2004. 
Kraft, B. J., Mayer, L. A., Simpkin, P. G., and Goff, J. A., "In-situ measurement of geoacoustic sediment properties: An example from the ONR Mine Burial Program, Martha's Vineyard Coastal Observatory," J. Acoust. Soc. Am., Vol. 113, No. 4, Pt. 2, pg. 2318, April 2003.

Kraft, B. J., Mayer, L. A., Simpkin, P. G., Goff, J. A., Schwab, B., and Jenkins, C., In-situ measurement of sediment properties and relationship to backscatter: an example from the ONR mine burial program, Martha's Vineyard Coastal Observatory," EOS Trans. AGU, 83(47), Abstract OS61A0182, December 2002.

Kraft, B. J., Mayer, L. A., Simpkin, P. G., and Goff, J. A., Comparison of in-situ compressional wave speed and attenuation measurements to Biot--Stoll model predictions, J. Acoust. Soc. Am., Vol. 112, No. 5, Pt. 2, pg. 2254, November 2002. 